\title{
KANDUNGAN LOGAM BERAT PADA IKAN YANG DITANGKAP DARI MUARA SUNGAI KAHAYAN, KALIMANTAN TENGAH
}

Nandang Priyanto*) dan Jovita Tri Murtini*

\begin{abstract}
ABSTRAK
Telah dilakukan penelitian residu logam berat pada ikan di perairan muara Sungai Kahayan, Kalimantan Tengah. Pengambilan sampel dilakukan pada bulan April dan September 2005 di 6 stasiun pengamatan ( 3 stasiun berada di tepi muara sungai dan 3 stasiun lainnya berjarak 1 mil dari tepi muara sungai). Contoh yang diambil adalah ikan, air dan sedimen. Parameter yang diamati adalah logam berat $(\mathrm{Hg}, \mathrm{Cd}, \mathrm{Cu}$ dan $\mathrm{Pb}$ ), kualitas air (suhu, kecerahan, salinitas, $\mathrm{pH}, \mathrm{DO}$, $B O D$ dan $C O D$ ) dan unsur hara (amonia, nitrit, nitrat, sulfit dan fosfat). Kandungan logam berat pada ikan masih di bawah ambang batas, tetapi sudah harus mendapat perhatian karena kandungannya sudah cukup tinggi. Kandungan $\mathrm{Hg}, \mathrm{Pb}$ dan $\mathrm{Cd}$ pada sampel air yang diambil dari muara Sungai Kahayan sudah ada yang melebihi ambang batas yang dijinkan, sedangkan kandungan $\mathrm{Cu}$ pada semua sampel yang diteliti telah melebihi batas ambang. Sementara itu kandungan $\mathrm{Hg}, \mathrm{Pb}, \mathrm{Cd}$ dan $\mathrm{Cu}$ pada sedimen masih di bawah batas ambang yang diijinkan. Unsur pencemar lain secara umum masih cukup baik, meskipun pada bulan September kadar amonia sudah melebihi ambang batas.
\end{abstract}

\section{ABSTRACT: Studies on heavy metals content of fishes caught from Kahayan estuary,} Central Kalimantan. By: Nandang Priyanto dan Jovita Tri Murtini

Studies on heavy metal residues in fishes caught from Kahayan River were carried out. Samples were taken on April and September 2005 at 6 stations (3 stations were located on Kahayan estuary bank while the others were 1 mile from the Kahayan River bank). Samples taken were fishes, water and sediment. Parameters observed were heavy metals ( $\mathrm{Hg}, \mathrm{Pb}, \mathrm{Cd}$ and $\mathrm{Cu}$ ), water quality (temperature, transparancy, salinity, $\mathrm{pH}, D \mathrm{D}, \mathrm{BOD}$ and $C O D$ ) and nutrients (ammonia, nitrite, nitrate, sulphite and phosphat). Result of the study showed that heavy metals content in fish were still below the MRL (Maximum Residue Limit), while in water on some stations were over the $M R L$. On the other hand, the Cu content in water samples collected from all stations were over the MRL. However, heavy metals content in sediment ( $\mathrm{Hg}, \mathrm{Pb}, \mathrm{Cd}$ and $\mathrm{Cu}$ ), were still below the MRL. In general, other pollutants were still at low level, except ammonia content in September which was over the standard limit.

\section{KEYWORDS: ' heavy metal, Kahayan waters, fish, water quality}

\section{PENDAHULUAN}

Sungai Kahayan di Kalimantan Tengah memiliki potensi yang sangat potensial bagi pengembangan berbagai kegiatan perekonomian seperti perikanan, transportasi, industri, pertambangan maupun kegiatan lainnya. Warga yang tinggal di sepanjang DAS Kahayan tersebut, memang mendapat keuntungan ekonomis dari kegiatan tersebut namun di sisi lain, pembuangan limbah secara terus menerus dapat menyebabkan turunnya kualitas perairan dan mengakibatkan terganggunya ekosistem alami wilayah tersebut.

Di Sungai Kahayan sekurang-kurangnya terdapat 6.000 unit mesin milik penambang emas tanpa ijin (PETI) yang beroperasi, belum lagi di sungai yang lain. Diperkirakan jumlah mesin penambang liar di seluruh Kalteng saat kemarau mencapai 10.000 unit yang dioperasikan. Dalam jangka waktu 3 bulan setiap mesin membuang satu kilogram merkuri, berarti tiap tahunnya aktivitas penambangan liar membuang merkuri sekitar 10-24 ton (Nicodemus, 2003). Industri pertambangan terutama logam mulia seperti emas, umumnya menggunakan merkuri untuk mengikat emas (proses amalgamisasi). Biasanya, limbah proses amalgamisasi (tailing) tersebut dibuang ke badan sungai yang selanjutnya mengalir ke laut. Selain itu, berbagai kegiatan industri serta padatnya jalur transportasi air di sepanjang DAS Kahayan berpotensi menyebabkan terjadinya peningkatan cemaran logam berat seperti merkuri $(\mathrm{Hg})$, timbal $(\mathrm{Pb})$, kadmium (Cd) dan tembaga (Cu). Hal ini disebabkan

\footnotetext{
*) Peneliti pada Balai Besar Riset Pengolahan Produk dan Bioteknologi Kelautan dan Perikanan
} 
senyawa logam berat banyak digunakan dalam berbagai industri baik sebagai bahan baku, katalisator, fungisida maupun bahan aditif lainnya (Hutagalung, et al., 1997). Pencemaran logam berat di perairan dapat menyebabkan biota yang hidup di dalamnya menjadi tercemar pula. Hal ini dapat terjadi karena biota dapat mengakumulasikan residu logam berat melalui rantai makanannya yang akan menyebabkan keracunan dan akhirnya membahayakan kesehatan manusia bila mengkomsumsinya.

Hasil penelitian tahun 2002 (Nicodemus, 2003) menunjukkan bahwa kandungan merkuri di air Sungai Kahayan mencapai $5 \mathrm{ppb}$, telah melebihi ambang batas yang ditentukan yaitu 2 ppb untuk air sungai Sementara itu merkuri untuk ikan lokal yaitu ikan Baung (Macrones remorus) yang hidup di dasar sunga telah mencapai $0,68 \mathrm{ppm}$, padahal ambang batasnya sebesar 0,5 ppm. Adapun kadar merkuri pada sedimen di dasar Sungai Kahayan telah mencapai 0,79 ppm. Menurut National d' Observation, 1981 ambang batas merkuri untuk sedimen di perairan ditetapkan sebesar 0,35 ppm. Sehubungan dengan hal tersebut maka perlu dilakukan penelitian pada lokasi-lokasi yang masih berpotensi tercemar logam berat seperti muara Sungai Kahayan Kalimantan Tengah untuk mengetahui kualitas perairan setempat serta dampaknya terhadap sumber daya perikanan yang ada.

\section{BAHAN DAN METODE}

Sampel utama yang diamati dalam penelitian ini adalah ikan, air dan sedimen yang diambil dari 6 stasiun pengamatan. Waktu pengambilan contoh dilakukan dua kali untuk setiap stasiun yaitu pada bulan April dan September 2005. Pengambilan contoh dilakukan di tepi muara sungai sebanyak 3 stasiun dan 1 mil dari tepi muara sungai sebanyak 3 stasiun. Posisi setiap stasiun pengamatan ini ditentukan dengan menggunakan alat Global Positioning System (GPS). Posisi setiap stasiun ini disajikan dalam Tabel 1.

Parameter yang diamati adalah kandungan logam berat $(\mathrm{Hg}, \mathrm{Cd}, \mathrm{Cu}$, dan $\mathrm{Pb}$ ), kualitas air (suhu, kecerahan, salinitas, $\mathrm{pH}, \mathrm{DO}, \mathrm{BOD}$ dan $\mathrm{COD}$ ), serta unsur hara (nitrat, nitrit, fosfat, sulfat dan amonia). Pengambilan contoh air dilakukan dengan menggunakan alat water sampler (Nansen), contoh sedimen menggunakan alat pengambil sedimen ( $g r a b)$, sedangkan sampel ikan diperoleh dari nelayan setempat. Contoh yang diperoleh tersebut selanjutnya diawetkan (Hutagalung et al., 1997). Contoh air diawetkan dengan asam nitrat $\left(\mathrm{HNO}_{3}\right)$ sedangkan ikan dan sedimen diawetkan pada suhu dingin. Preparasi terhadap contoh logam berat menggunakan prosedur Hutagalung et al. (1997), sedangkan untuk analisisnya menggunakan alat Atomic Absorbtion Spectropho-

Tabel 1. Posisi stasiun pengambilan sampel di perairan muara Sungai Kahayan

Table 1. Sampling stations position in Kahayan estuary waters

\begin{tabular}{|c|c|c|c|}
\hline $\begin{array}{l}\text { Stasiun/ } \\
\text { Station }\end{array}$ & $\begin{array}{l}\text { Lintang se latan/ } \\
\text { South latitude }\end{array}$ & $\begin{array}{l}\text { Bujur timurl } \\
\text { East meridian }\end{array}$ & $\begin{array}{l}\text { Keterangan/ } \\
\text { Note }\end{array}$ \\
\hline 1 & $S 3^{0} 22^{\prime} 650^{\prime \prime}$ & E $114^{\circ} 04^{\prime} 550^{\prime \prime}$ & Tepi muara sungai/Estuary bank \\
\hline 2 & $S 3^{\circ} 22^{\prime} 550^{\prime \prime}$ & E $114^{\circ} 05^{\prime} 500^{\prime \prime}$ & Tepi muara sungai/Estuary bank \\
\hline 3 & $S 3^{\circ} 22^{\prime} 442^{\prime \prime}$ & $E 114^{\circ} 06^{\prime} 268^{\prime \prime}$ & Tepi muara sungai/Estuary bank \\
\hline 4 & $S 3^{0} 23^{\prime} 700^{\prime \prime}$ & E $114^{0} 04^{\prime} 650^{\prime \prime}$ & $\begin{array}{c}1 \text { mil dari tepi muaral } \\
1 \text { mile from the estuary bank }\end{array}$ \\
\hline 5 & $S 3^{0} 23^{\prime} 600^{\prime \prime}$ & $E^{2} 114^{0} 05^{\prime} 600^{\prime \prime}$ & $\begin{array}{l}1 \text { mil dari tepi muara/ } \\
1 \text { mile from the estuary bank }\end{array}$ \\
\hline 6 & $S 3^{0} 23^{\prime} 500^{\prime \prime}$ & $\mathrm{E} 114^{\circ} 06^{\prime} 550^{\prime \prime}$ & $\begin{array}{l}1 \text { mil dari tepi muaral } \\
1 \text { mile from the estuary bank }\end{array}$ \\
\hline
\end{tabular}


Tabel 2. Hasil analisis kandungan residu logam berat pada berbagai jenis ikan di perairan muara Sungai Kahayan

Table 2. Heavy metals content of fish samples collected from Kahayan estuary waters

\begin{tabular}{|c|c|c|c|c|c|}
\hline $\begin{array}{l}\text { Bulan/ } \\
\text { Month }\end{array}$ & Jenis ikan/Kind of fish & $\begin{array}{c}\mathrm{Hg} \\
(\mathrm{ppb})\end{array}$ & $\begin{array}{c}\mathrm{Pb} \\
(\mathrm{ppb})\end{array}$ & $\begin{array}{c}C d \\
(p p b)\end{array}$ & $\begin{array}{c}\mathrm{Cu} \\
(\mathrm{ppb})\end{array}$ \\
\hline \multirow{8}{*}{$\begin{array}{l}\text { April/ } \\
\text { April }\end{array}$} & Kepah/Mussel & 23.49 & 115.03 & 70.30 & 415.30 \\
\hline & Bulu bulu/Polynemus heptadactylus C.V. & 164.33 & 39.55 & 33.30 & 98.20 \\
\hline & Pirang pirang/Setipinna melanochir Blkr & 245.56 & 45.23 & 18.87 & 116.50 \\
\hline & Kiper laut/Scatophagus argus $B I$ & 239.75 & 30.40 & 24.61 & 237.60 \\
\hline & Lais/Cryptopterus lais Blkr & 433.31 & 60.30 & 24.43 & 80.56 \\
\hline & Sembilang/Plotosus cainus Ham. Buck & 324.00 & 34.40 & 15.84 & 58.19 \\
\hline & Udang putih/Penaeus merquiensis & 104.95 & 38.27 & 51.72 & 1232.00 \\
\hline & Baga baga/Parambassis apogonoides & 80.10 & 48.40 & 17.37 & 104.90 \\
\hline \multirow{9}{*}{$\begin{array}{l}\text { September/ } \\
\text { September }\end{array}$} & Selongsongan/Otholithoides biauritus cantor & 20.14 & 7.17 & 11.27 & 4.53 \\
\hline & Gulamah/Pseudociena amoyensis C.V & 6.65 & 9.90 & 6.87 & 131.75 \\
\hline & Mata gelap/Gerres abbreviateus Blkr & 3.61 & 8.90 & 10.28 & 8.15 \\
\hline & Sebelah/Cynoglossus lingua & 3.63 & 11.23 & 21.26 & 10.44 \\
\hline & Udang putih/Penaeus merquiensis & 4.74 & 13.41 & 19.09 & 37.93 \\
\hline & Udang windu/Penaeus monodon & 3.92 & 11.45 & 14.86 & 56.25 \\
\hline & Kakap putih/Lates calcarifer bloch & 7.94 & 10.70 & 4.90 & 7.95 \\
\hline & Kepiting/Scylla serrata & 3.35 & 1.86 & 83.67 & 491.75 \\
\hline & Kepah/Mussel & 4.05 & 3.48 & 127.35 & 46.57 \\
\hline
\end{tabular}

tometer (AAS) Perkin Elmer A800 di Laboratorium Balai Besar Riset Pengolahan Produk dan Bioteknologi Kelautan dan Perikanan, Jakarta. Analisis kualitas air dan unsur hara dilakukan di tempat setelah contoh diperoleh. Untuk mengukur salinitas menggunakan alat refraktometer, $\mathrm{pH}$ menggunakan $\mathrm{pH}$ meter, dan DO, COD serta unsur hara dilakukan menggunakan alat kolorimeter (Hach, 1999). Hasil analisis logam berat kemudian dibandingkan dengan ambang batas yang diijinkan baik untuk ikan (Ditjen POM, 1989) maupun untuk perairannya (Anon., 1990). Berdasarkan ketentuan dari WHO/FAO dalam JECFA, 2003, batasan asupan ikan yang terkontaminasi logam berat dapat ditentukan melalui Provisional Tolerable Weekly Intake (PTWI).

\section{HASIL DAN BAHASAN}

Hasil analisis residu logam berat pada ikan segar yang berasal dari muara Sungai Kahayan, Kalimantan Tengah yang diambil pada bulan April dan September 2005 disajikan dalam Tabel 2. Terlihat bahwa kecenderungan kandungan logam berat $(\mathrm{Hg}, \mathrm{Pb}, \mathrm{Cd}$ dan $\mathrm{Cu}$ ) pada bulan April lebih besar dibandingkan bulan September, hal ini dikarenakan pada bulan April perairan sedang surut sehingga logam berat yang terkonsentrasi dalam air akan diabsorbsi lebih banyak di tubuh ikan. Hasil pengukuran ini sejalan dengan hasil analisis kandungan logam berat perairan pada bulan April yang juga lebih besar (Tabel 3). Menurut Ansari et al. (2004), tingkat konsentrasi logam berat 
Tabel 3. Hasil analisis kandungan residu logam berat pada air di perairan muara Sungai Kahayan

Table 3. Heavy metals content of water in Kahayan estuary waters

\begin{tabular}{cccccc}
\hline $\begin{array}{c}\text { Bulan/ } \\
\text { Month }\end{array}$ & $\begin{array}{c}\text { Stasiun/ } \\
\text { Station }\end{array}$ & $\begin{array}{c}\mathrm{Hg} \\
(\mathbf{p p b})\end{array}$ & $\begin{array}{c}\mathrm{Pb} \\
(\mathbf{p p b})\end{array}$ & $\begin{array}{c}\mathrm{Cd} \\
(\mathbf{p p b})\end{array}$ & $\begin{array}{c}\mathrm{Cu} \\
(\mathbf{p p b})\end{array}$ \\
\hline & 1 & 1.37 & 32.25 & 6.46 & 1530 \\
$\begin{array}{c}\text { April/ } \\
\text { April }\end{array}$ & 2 & 2.99 & 15.46 & 7.12 & 1020 \\
& 3 & 3.60 & 34.10 & 6.51 & 910 \\
& 4 & 5.17 & 22.23 & 9.31 & 1060 \\
& 5 & 1.68 & 13.44 & 8.77 & 910 \\
& 1 & 0.88 & 6.49 & 10.61 & 960 \\
\hline September/ & 2 & 2.36 & 17.20 & 57.89 & 870 \\
\hline September & 3 & 2.30 & 14.00 & 57.44 & 820 \\
& 5 & 1.58 & 20.90 & 46.55 & 700 \\
& 5 & 0.95 & 45.00 & 52.67 & 630 \\
& 5 & 1.69 & 15.30 & 49.46 & 690 \\
\hline
\end{tabular}

") Catatan/note: Contoh tidak dapat diambil di stasiun 4 karena gelombang sangat besar/ Samples could not be taken at station 4 due to the high wave

pada organisme air seringkali proporsional dengan tingkat konsentrasi logam berat pada perairannya, sehingga dapat digunakan sebagai indikator biologi pencemaran logam berat. Kandungan merkuri pada ikan berkisar 3,35-433,31ppb yang berarti masih di bawah ambang batas yang diijinkan (500 ppb). Namun demikian beberapa jenis ikan yang diambil pada bulan April kandungan merkurinya sudah cukup tinggi (di atas $100 \mathrm{ppb}$ ) hingga perlu mendapat perhatian serius karena sifat akumulatif logam berat ini dalam tubuh manusia. Sementara itu, kandungan logam berat (Cd, $\mathrm{Pb}$ dan $\mathrm{Cu}$ ) masih cukup rendah dan di bawah ambang batas yang ditentukan. Menurut Ditjen POM (1989), ambang batas $\mathrm{Hg}$ adalah 500 ppb, $\mathrm{Pb} 2000$ ppb, Cd 1000 ppb, dan Cu 20000 ppb.

Berdasarkan ketentuan JECFA yang ditetapkan WHO/FAO tentang batas toleransi komsumsi bahan pangan yang terkontaminasi logam berat, sebagai contoh, ikan Lais (Cryptopterus lais, Blkr) yang mempunyai kandungan $\mathrm{Hg}$ 433,31 ppb maka konsumsinya dibatasi hanya sebesar $692,34 \mathrm{~g} /$ minggu. Batas maksimum konsumsi bahan pangan yang terkontaminasi residu $\mathrm{Hg}$ berdasarkan Provisional Tolerable Weekly Intake (PTWI) adalah 300 $\mu \mathrm{g} / \mathrm{minggu} / 60 \mathrm{~kg}$ berat badan (Anon., 2003).

Kandungan logam berat $(\mathrm{Hg}, \mathrm{Pb}$ dan $\mathrm{Cu}$ ) pada sampel air muara di Sungai Kahayan untuk bulan April dan September dapat dilihat pada Tabel 3. Data penelitian menunjukkan kandungan $\mathrm{Hg}, \mathrm{Pb}$ dan $\mathrm{Cu}$ cenderung lebih tinggi pada bulan April dibandingkan bulan September, hal ini dikarenakan pada bulan April perairan sedang surut akibat kemarau sehingga logam berat yang terlarut dalam air mengalami pemekatan. Kandungan $\mathrm{Hg}$ dalam air yang diambil baik pada bulan April maupun September berkisar 0,88-5,17 ppb dan beberapa stasiun sudah melebihi ambang batas yang diijinkan (2 ppb), begitu juga dengan $\mathrm{Cd}$ pada bulan September di semua stasiun sudah melebihi ambang batas yang diijinkan (10 ppb). Tingginya kandungan Cd kemungkinan berasal dari limpasan limbah pertanian (pupuk fosfat) dan limbah industri (tekstil, meubel kayu) yang ada di sepanjang DAS Kahayan. Menurut Murtini \& Ariyani (2005), selain berasal dari pencemaran, keberadaan Cd dapat juga berasal dari 
peluruhan bebatuan. Sementara itu kandungan $\mathrm{Pb}$ umumnya tinggi dan beberapa stasiun sudah melebihi ambang batas yang diijinkan (20 ppb). Sumber utama cemaran $\mathrm{Pb}$ kemungkinan berasal dari perahu-perahu motor yang digunakan sebagai sarana transportasi air. Dari hasil analisis juga diketahui bahwa kandungan Cu berkisar 630-1530 ppb, ini berarti telah melebihi ambang batas yang diijinkan (20 ppb). Tingginya kandungan $\mathrm{Cu}$ diduga berasal dari industri pengolahan kayu dan galangan kapal sebagai campuran bahan untuk pengawet. Di samping itu tingginya logam $\mathrm{Cu}$ berkaitan dengan mobilitas Cu yang merupakan unsur esensial bagi tumbuhan (Amin, 2001) yang menjadikan logam Cu secara alamiah pun cukup tinggi. Menurut PP RI No. 20 tahun 1990, ambang batas logam berat dibandingkan bulan September, hal ini kemungkinan disebabkan oleh proses pengendapan lumpur di perairan hingga logam berat terakumulasi di sedimen. Kandungan alamiah logam berat dalam sedimen menurut National d' Observation, RNO (1981) yaitu $\mathrm{Hg}$ 20-350 ppb, Pb10000-70000 ppb, Cd 100-2000 ppb dan Cu 5000-30000 ppb (Razak, 1986 dalam Fajri, 2001).

Hasil pengamatan kondisi fisik perairan muara Sungai Kahayan pada bulan April dan September 2005 disajikan dalam Tabel 5. Terlihat $\mathrm{pH}$ pada bulan April cenderung bersifat asam bila dibandingkan bulan September. Hal ini disebabkan debit perairan pada bulan April menurun dan adanya lahan gambut di

Tabel 4. Hasil analisis kandungan logam berat pada sedimen di perairan muara Sungai Kahayan

Table 4. Heavy metals content of sediment collected of Kahayan estuary waters

\begin{tabular}{cccccc}
\hline $\begin{array}{c}\text { Bulan/ } \\
\text { Month }\end{array}$ & $\begin{array}{c}\text { Stasiun/ } \\
\text { Station }\end{array}$ & $\begin{array}{c}\mathrm{Hg} \\
(\mathbf{p p b})\end{array}$ & $\begin{array}{c}\mathrm{Pb} \\
(\mathbf{p p b})\end{array}$ & $\begin{array}{c}\mathrm{Cd} \\
(\mathbf{p p b})\end{array}$ & $\begin{array}{c}\mathrm{Cu} \\
(\mathbf{p p b})\end{array}$ \\
\hline & 1 & 1.10 & 93.75 & 69.97 & 2120 \\
April/ & 2 & 1.91 & 137.35 & 32.86 & 3050 \\
April & 3 & 4.38 & 143.15 & 37.04 & 2610 \\
& 4 & 2.02 & 76.30 & 42.84 & 3050 \\
& 5 & 4.79 & 121.00 & 45.44 & 3030 \\
& 6 & 15.85 & 91.90 & 182.70 & 2520 \\
\hline \multirow{3}{*}{ September/ } & 1 & 6.66 & 9.79 & 69.05 & 1050 \\
September & 2 & 22.35 & 10.48 & 48.09 & 1080 \\
& 3 & 6.83 & 7.16 & 41.19 & 640 \\
& 5 & 6.03 & 9.21 & 42.44 & 910 \\
& 6 & 9.44 & 6.43 & 137.6 & 910 \\
\hline
\end{tabular}

") Catatan/note: Contoh tidak dapat diambil di stasiun 4 karena gelombang sangat besar/ Samples could not be taken at station 4 due to the high wave

dalam air untuk usaha perikanan yaitu $\mathrm{Hg} 2 \mathrm{ppb}, \mathrm{Pb}$ 20 ppb, Cd 10 ppb dan Cu 20 ppb (Anon., 1990).

Pada Tabel 4 disajikan hasil analisis logam berat dalam sedimen di perairan muara Sungai Kahayan pada bulan April dan September 2005. Kandungan logam berat ( $\mathrm{Hg}, \mathrm{Pb}, \mathrm{Cd}$ dan $\mathrm{Cu}$ ) masih cukup rendah dan belum melebihi ambang batas yang diijinkan. Terlihat kandungan logam berat ( $\mathrm{Pb}, \mathrm{Cd}$ dan $\mathrm{Cu}$ ) dalam sedimen cenderung lebih tinggi pada bulan April
Kalimantan Tengah juga memberikan efek pada tingkat keasaman perairan. Rendahnya kecerahan air yang hanya sampai kedalaman $20 \mathrm{~cm}$ (stasiun 3 bulan September) kemungkinan disebabkan banyaknya bahanbahan tersuspensi yang terbawa aliran sungai menuju muara, hingga air terlihat keruh dan warnanya kecoklatan. Salinitas pada bulan April sangat rendah dan mendekati netral tetapi pada bulan September salinitas cukup tinggi. Hal ini disebabkan pada bulan 
Tabel 5. Kondisi fisik perairan muara Sungai Kahayan

Table 5. Physical condition of Kahayan estuary waters

\begin{tabular}{ccccccccc}
\hline $\begin{array}{c}\text { Bulan/ } \\
\text { Month }\end{array}$ & $\begin{array}{c}\text { Stasiun/ } \\
\text { Station }\end{array}$ & $\begin{array}{c}\text { Suhu/Temp. } \\
\left({ }^{\circ} \mathbf{C}\right)\end{array}$ & $\mathbf{p H}$ & $\begin{array}{c}\text { Kecerahan/ } \\
\text { Transparancy } \\
(\mathbf{c m})\end{array}$ & $\begin{array}{c}\text { Salinitas/ } \\
\text { Salinity } \\
(\mathbf{p p t})\end{array}$ & $\begin{array}{c}\text { DO } \\
(\mathbf{p p m})\end{array}$ & $\begin{array}{c}\text { BOD } \\
(\mathbf{m g} / \mathrm{L})\end{array}$ & $\begin{array}{c}\text { COD } \\
(\mathbf{p p m})\end{array}$ \\
\hline & 1 & 28.8 & 4.5 & 50 & 0.0 & 5.6 & 0.94 & 312.0 \\
& 2 & 29.4 & 5.4 & 25 & 0.2 & 7.2 & 2.43 & 100.8 \\
April/ & 3 & 30.1 & 6.5 & 50 & 6.0 & 24.3 & 17.10 & 216.0 \\
April & 4 & 31.0 & 5.5 & 50 & 10.0 & 25.2 & 19.10 & 632.0 \\
& 5 & 31.1 & 7.1 & 50 & 2.1 & 22.3 & 16.20 & 336.0 \\
& 6 & 31.0 & 4.8 & 50 & 5.0 & 25.8 & 14.90 & 268.0 \\
\hline & 1 & 28.2 & 7.8 & 40 & 20.0 & 4.1 & 1.50 & 93.0 \\
& 2 & 29.4 & 7.8 & 50 & 20.0 & 4.3 & 2.00 & 89.0 \\
September/ & 3 & 28.0 & 7.7 & 20 & 15.0 & 3.9 & 1.70 & 80.0 \\
September $\left.{ }^{*}\right)$ & 5 & 28.3 & 7.9 & 40 & 24.0 & 3.4 & 0.20 & 66.0 \\
& 6 & 28.0 & 7.9 & 45 & 20.0 & 4.0 & 0.60 & 59.0 \\
\hline
\end{tabular}

*) Catatan/note: Contoh tidak dapat diambil di stasiun 4 karena gelombang sangat besar/ Samples could not be taken at station 4 due to the high wave

Tabel 6. Hasil analisis kandungan unsur pencemar lain di muara Sungai Kahayan

Table 6. Concentration of other pollutant in Kahayan estuary waters

\begin{tabular}{cccccc}
\hline $\begin{array}{c}\text { Bulan/ } \\
\text { Month }\end{array}$ & $\begin{array}{c}\text { Stasiun/ } \\
\text { Station }\end{array}$ & $\begin{array}{c}\mathrm{Hg} \\
(\mathbf{p p b})\end{array}$ & $\begin{array}{c}\mathrm{Pb} \\
(\mathbf{p p b})\end{array}$ & $\begin{array}{c}\mathrm{Cd} \\
(\mathbf{p p b})\end{array}$ & $\begin{array}{c}\mathrm{Cu} \\
(\mathbf{p p b})\end{array}$ \\
\hline & 1 & 1.10 & 93.75 & 69.97 & 2120 \\
April/ & 2 & 1.91 & 137.35 & 32.86 & 3050 \\
April & 3 & 4.38 & 143.15 & 37.04 & 2610 \\
& 4 & 2.02 & 76.30 & 42.84 & 3050 \\
& 5 & 4.79 & 121.00 & 45.44 & 3030 \\
& 6 & 15.85 & 91.90 & 182.70 & 2520 \\
\hline \multirow{3}{September/}{} & 1 & 6.66 & 9.79 & 69.05 & 1050 \\
September & 2 & 22.35 & 10.48 & 48.09 & 1080 \\
& 3 & 6.83 & 7.16 & 41.19 & 640 \\
& 5 & 6.03 & 9.21 & 42.44 & 910 \\
& 6 & 9.44 & 6.43 & 137.6 & 910 \\
\hline
\end{tabular}

") Catatan/note: Contoh tidak dapat diambil di stasiun 4 karena gelombang sangat besar/ Samples could not be taken at station 4 due to the high wave 
April air laut surut dan pada bulan September air laut pasang sehingga menyebabkan naiknya air laut ke sungai. Kandungan BOD masih cukup baik, di bawah $20 \mathrm{mg} / \mathrm{L}$. Kandungan COD cukup tinggi dan sudah melewati ambang batas untuk perikanan yaitu $40 \mathrm{mg} /$ $\mathrm{L}$, tetapi oksigen terlarut (DO) masih cukup baik di atas $3 \mathrm{mg} / \mathrm{L}$. Adapun temperatur berkisar 28,0-31,1 ${ }^{\circ} \mathrm{C}$, merupakan kondisi yang baik untuk kehidupan ekosistem perairan. Terjadinya gelombang sangat besar pada bulan September yang menyebabkan contoh di stasiun 4 tidak dapat diambil karena kondisi kapal yang tidak memenuhi persyaratan menuju ke lokasi.

Pada Tabel 6 disajikan hasil analisis kandungan unsur pencemar lain di muara Sungai Kahayan pada bulan April dan September 2005. Terlihat kecenderungan kandungan nitrit, nitrat dan fosfat pada bulan September lebih besar dibandingkan bulan April, sedangkan sulfit mendekati nol. Tingginya kandungan nitrit, nitrat dan fosfat diperkirakan berasal dari limpasan bahan-bahan organik dari daratan sewaktu hujan. Kandungan nitrit yang berkisar 0-0,047 $\mathrm{mg} / \mathrm{L}$, masih di bawah ambang batas yang diijinkan $(0,06 \mathrm{mg} / \mathrm{L})$ kecuali pada stasiun 6 pada bulan April sebesar 0,080 mg/L. Kandungan amonia berkisar 0$0,19 \mathrm{mg} / \mathrm{L}$ umumnya sudah di atas ambang batas yang diijinkan $(0,02 \mathrm{mg} / \mathrm{L})$. Tingginya kandungan amonia ini merupakan salah satu indikasi adanya pencemaran (Effendi, 2003). Menurut PP RI No. 20 tahun 1990, kandungan maksimum nitrit, amonia dan sulfit dalam air bagi usaha perikanan yaitu nitrit 0,06 ppm, amonia 0,02 ppm dan sulfit 0,002 ppm (Anon., 1990).

\section{KESIMPULAN}

Dari hasil penelitian dapat disimpulkan bahwa kandungan logam berat pada ikan yang ditangkap di muara Sungai Kahayan masih di bawah ambang batas diijinkan, tetapi sudah harus mendapat perhatian karena sudah cukup tinggi. Kandungan logam berat ( $\mathrm{Hg}, \mathrm{Pb}$ dan $\mathrm{Cd}$ ) dalam air di perairan muara Sungai Kahayan pada beberapa stasiun yang diteliti sudah ada yang melebihi ambang batas yang diijinkan, sedangkan kandungan logam berat Cu dalam air pada semua stasiun sudah melebihi ambang batas yang diijinkan. Sementara itu kandungan logam berat $(\mathrm{Hg}$, $\mathrm{Pb}, \mathrm{Cd}$ dan $\mathrm{Cu}$ ) dalam sedimen masih di bawah ambang batas yang diijinkan. Unsur pencemar lain pada umumnya masih cukup baik, meskipun pada bulan September kadar amonia sudah melebihi ambang batas yang diijinkan.

\section{DAFTAR PUSTAKA}

Amin, B. 2001. Akumulasi dan distribusi logam berat $\mathrm{Pb}$ dan Cu pada mangrove (Avicennia marina) di Perairan Pantai Dumai, Riau. http://www.unriac.id/ jurnal/jurnal_natur/vo/4(1)/Bintal. Diakses $12 \mathrm{Mei}$ 2006.

Anonim. 1990. Peraturan Pemerintah RI No. 20 Tahun 1990. Tanggal 5 Juni 1990 Tentang Pengendalian Pencemaran Air.

Anonymous. 2003. Summary and conclusion of the sixtyfirst meeting of joint FAO/WHO expert commitee on food additives. www. who.int/pcs/jecfa. Assesed June 2, 2006.

Ansari, T.M., Marr, I.L. and Tarig, N. 2004. Heavy metals in marine pollutan perspective-a mini review. $J$. Applied Sci. 4(1): 1-20.

Ditjen POM. 1989. Keputusan Ditjen Pengawasan Obat dan Makanan No.13725/B/SK.VII/1989.

Effendi, H. 2003. Telaah Kualitas Air Bagi Pengelolaan Sumber Daya dan Lingkungan Perairan. Kanisius, Yogyakarta. $258 \mathrm{pp}$.

Fajri, N.E. 2001. Analisis Kandungan Logam Berat Hg, $\mathrm{Cd}$ dan $\mathrm{Pb}$ dalam Air Laut, Sedimen, dan Tiram (Carassostrea cucullata), di Perairan Pesisir Kecamatan Pedes, Kabupaten Karawang, Jawa Barat. Tesis. Program Pascasarjana. IPB. Bogor. 59 pp.

Hach. 1999. Dataloging Colorimeter Handbook. Hach Company, PO Box 608. Loveland, Co.

Hutagalung, H.P., Setiapermana, D., dan Riyono, S.H. 1997. Metode Analisis Air Laut, Sedimen dan Biota. Buku 2. Puslitbang Oseanologi. LIPI. Jakarta. 182 pp.

Murtini, J.T. dan Ariyani, F. 2005. Kandungan logam berat kerang darah (Anadara granosa) dan kualitas perairan di Tanjung Pasir, Jawa Barat. J. Penel. Perik. Indonesia. 11(8): 39-45.

Nicodemus, M. 2003. Kerusakan lingkungan akibat pertambangan mas tanpa ijin (PETI).http:// tumoutou.net/ekoton. Diakses 13 Mei 2006. 